\author{
Michele de Freitas Faria de Vasconcelos \\ Universidade Federal de Sergipe
}

\title{
Cuidado com corpos: um olhar (de gênero) para políticas de saúde
}

Resumo: O texto se propõe a pensar as políticas públicas de saúde (mental) e seu mandato institucional de inclusão social como fazendo parte de um cenário mais amplo da biopolítica de face (neo)liberal, em que se governa a vida e as condutas humanas para o mercado. Nesse contexto, aqueles/as que falharam ou não se engajaram em fazer de seus corpos empresas figuram como novos doentes, anormais, infames. O escopo das práticas assistenciais oferecidas pelas políticas de saúde tende a ser, assim, o de inscrever tais vidas infames em pedagogias, em particular, de gênero e de sexualidade, incluindo-as na economia social de mercado. Procurando por ampliações do corpo e da vida, desenvolveu-se um olhar (de gênero) sobre modos de produção de cuidado em saúde, em particular, em álcool e outras drogas.

Palovras-chave: biopolítica; políticas públicas de saúde; inclusão social; corpo; gênero.

Copyright (c) 2015 by Revista Estudos Feministas.

${ }^{1}$ Michel FOUCAULT, 2008a, 2008b.

\section{Da produção de corpos cidadãos}

Por meio de um olhar (de gênero) sobre a produção de cuidado em saúde pública, mais especificamente em álcool e outras drogas, esse texto se propõe a pensar as políticas públicas de saúde (mental) e seu mandato institucional de inclusão social como fazendo parte de um cenário mais amplo da biopolítica de face (neo)liberal, em que se governa a vida e as condutas humanas para $o$ mercado. A partir do itinerário foucaultiano, nele se entende a governamentalidade como uma economia de produção de subjetividades e o governo estatal e mercadológico das condutas como um problema pedagógico, ou seja, um governo que se desenvolve a partir do acionamento de procedimentos pedagógicos. Para formar sujeitos governáveis ou (re)formar ingovernáveis, inscrevendo suas condutas no modelo econômico de existência, são necessários investimentos educacionais. ${ }^{1}$ Dessa forma, o 
2 Valerie, HARWOOD, 2009 ${ }^{3}$ FOUCAULT, 2001a.

${ }^{4}$ FOUCAULT, 2008b, p. 315.

${ }^{5}$ FOUCAULT, 2008b, p. 222.

${ }^{\circ}$ FOUCAULT, 2008b, p. 222. ${ }^{7}$ FOUCAULT, 2008b, p. 310.

${ }^{8}$ FOUCAULT, 2010 , p. $285-286$. governo das condutas parece traduzir-se em uma pedagogia das condutas, e esta em pedagogias corporais, pedagogias da vida, biopedagogias, ${ }^{2}$ uma vez que se trata de administrar corpos individuais e 0 social $^{3}$ a partir de prescrições sobre como se conduzir, como viver.

Tais pedagogias são compostas por um conjunto de processos de ensino e de aprendizagem que permeiam muitas instâncias e dimensões da vida em sociedade, por meio dos quais indivíduos são (trans)formados em sujeitos de uma cultura somático-empresarial. Em outros termos, é preciso formar capital humano: "é muito mais do lado do adquirido, ou seja, da constituição mais ou menos voluntária de um capital humano no curso da vida dos indivíduos, que se colocam todos os problemas", ${ }^{4}$ requerendo-se, assim, o acionamento de um Estado e de um mercado pedagogos: é preciso produzir fôrmas de ação, ensinar aos indivíduos e à população as condutas concernentes aos jogos de poder. Nesse sentido, se há intervencionismo social permanente e multiforme, é justamente como "condição histórica e social de possibilidade para uma economia de mercado", ${ }^{5}$ uma vez que é preciso formar capital-competência com vistas à "formalização da sociedade com base no modelo da empresa, ," "uma sociedade feita de unidades-empresas", deve-se produzir condutas governáveis, ou seja, tais condutas devem traduzir-se em condutas econômicas. Nessa direção, todas as questões de seguridade, de higiene pública, de proteção à saúde e ao bem-estar, de assistência, todas as políticas sociais e seus serviços são entendidos como elementos com possibilidade de incrementar o capital humano, ou seja, como elementos pedagógicos: porque é preciso formar empresários/as de si mesmos/as, porque é preciso alimentar o capital com vidas humanas.

O entendimento do governo das condutas como pedagogia parece oferecer uma pista importante para analisar o funcionamento das políticas sociais, em particular, as de saúde (mental), campo de minhas pesquisas: os serviços que as compõem, seus espaços, as prescrições clínico-institucionais que os regem, as diferentes atividades de gestão e de atenção realizadas, as relações entre as pessoas que vivem, convivem e circulam nas redes de saúde (mental), o modo como elas se comportam, os saberes e fazeres que ali se desenvolvem, o cuidado oferecido, os projetos terapêuticos construídos parecem operar como pedagogias, como elementos formadores de condutas: gestos são inscritos nos corpos, processos de ensino aprendizagem se tecem, organizando corpos, constituindo sujeitos, ou seja, formando profissionais e usuários/as, personagens que ali se encontram, "cada um com uma função, um lugar, um rosto bem-definido". ${ }^{8}$ 
9 Marlucy PARAísO, 2011.

10 Sandra CORAZZ e Tomaz SILVA, 2003, p. 11.

"Sérgio CARVALHO, 2009

12 CARVALHO, 2009.

\footnotetext{
${ }^{13}$ Estela SCHEINVAR, 2011, p. 146.
}

${ }^{14}$ Edson PASSETTI, 2003.

15 PASSETTI, 2003, p. 44.
As políicas sociais, em particular as de saúde, parecem, assim, constituírem-se como "um território de ensino", 9 tomando-se o ensinar como um processo que diz respeito à transmissão de informação, oferta, explicação, exposição, apresentação de conteúdos, conhecimentos, saberes e fazeres, conceitos, habilidades, competências, culturas, valores, modos de ser e de viver, condutas. Em outros termos, na medida em que ensinar se refere a um processo por meio do qual se busca governar condutas, produzir certas práticas, normalizar, hierarquizar, dividir sujeitos (quem sabe e quem não sabe, quem tem boa saúde e quem está doente, quem segue e quem não segue regras de conduta), as políticas de saúde e os serviços assistenciais que as compõem aparecem como territórios de ensino e formatação corporais. Mas o que essas políticas e seus serviços ensinam?

Tais políticas e serviços de saúde têm o escopo de formar sujeitos participativos, indexados a uma subjetividade cidadã. Os/as cidadãos/ãs participantes, os indivíduos críticos, conhecedores/as de seus direitos e deveres, responsáveis pelo seu corpo e autovigilantes de suas condutas funcionam como "avatares que povoam os territórios das pedagogias contemporâneas, ${ }^{10}$ " ocupadas em formar unidades-empresa, indivíduos que autopoliciam suas condutas e a dos outros, na busca pela qualidade de vida da população da qual fazem parte. Nos serviços que compõem as políticas sociais, chamadas políticas de inclusão, acionam-se pedagogias que ensinam uma "cidadania de sujeição"," a partir da qual se produz uma "autonomia regulada," 12 em que a garantia de direitos se faz acoplada ao controle das condutas. Ou seja, o direito à liberdade tem sua garantia subordinada ao cumprimento de deveres. Construída dessa forma, a condição do/a cidadão/ã de direitos "não é natural nem libertária, pois está condicionada a uma série de regras e lógicas assentadas na boa conduta." 13

A inclusão de corpos não cadastrados nos bancos de crédito no regime de cidadania, entendida como prática governamental, parece, então, ter o objetivo de incluir os excluídos como tal, trazê-los para espaços de participação e de convivência social num momento em que se exige participação social de todos/as. ${ }^{14}$ Passetti ${ }^{15}$ assinala a importância do estímulo e do reforço à participação também desses 'falsos vivos' nos jogos de poder: "a participação imperativa faz crer e faz produzir um indivíduo que precisa mostrar que está vivo. Se não estiver segundo a produção [...] está enquanto agente político de participação democrática [...] de todos (vivos e mortos produtivos)". Tal modo de inclusão, operado mediante aproximação física entre os corpos 'produtivos'/ativos e os não regrados, não 
${ }^{16}$ Maura LOPES, 2011.

permite que se prossiga falando em 'excluídos' - uma vez que 'estes' também compõem os mapas de intervenção estatal, já que as ovelhas desgarradas do controle das condutas devem retornar ao rebanho - nem em exclusão de acesso a redes assistenciais. ${ }^{16}$

Em outras palavras, conquista-se a condição cidadã por meio das pedagogias operadas, indexando-se a formaHomem a elas articuladas: O Homem, o homem da razão, possuidor de uma identidade indivisa e soberana, masculino, branco, adulto, heterossexual, trabalhador, viril, 'encorpado', sadio, 'chefe' de família que tem um nome a zelar e dá esse nome à família, que tem bens e patrimônios a honrar e que honram esse nome, que tem poder de consumo, de endividamento, cartão de crédito, que tem casa, endereço fixo, tudo isso the concedendo um local de poder e de autoridade como sujeito universal: a humanidade.

Esse texto será alinhavado pela narração de uma cena extraída de uma pesquisa que se ocupou do funcionamento de um Centro de Atenção Psicossocial para Álcool e outras Drogas (CAPS AD). Com ela, o que se aponta é para a fabricação de corpos 'desregrados' que fazem uso excessivo de álcool e outras drogas, como 'alcoólatras'e 'crackeiros' - ou, numa versão politicamente correta, alcoolistas e drogaditos -, como perigosos que precisam ser 'contidos' para não expor a população da vida saudável, regrada e ativa a riscos, corpos que, no limite, são matáveis justamente por conta dos perigos dessa exposição. Para cuidar dos corpos saudáveis, é preciso ter cuidado com esses corpos desviantes, contendoos. Quando a contenção é assistencial, esses corpos se transfiguram em doentes que precisam de cuidados, tendem a ser assistidos, submetidos a uma dinâmica institucional. Os corpos carimbados como alcoólatras e crackeiros tendem a ser aqueles que se mantêm fora da borda dos/as cidadãos/ãs contribuintes, entendidos, assim, como párias sociais, corpos demonizados, ou como corpos a serem socorridos, precisando de tutela institucional, corpos que, tomados ao cuidadoeducação de serviços de saúde, podem vir a ser cidadãos.

A cena narrada parece, assim, apontar para a conformação de uma determinada paisagem de cuidado-educação. Nela, o cuidado em álcool e outras drogas parece participar de um processo mais amplo de marcação, organização, recondução, normalização de corpos, nesse caso particular, daqueles que fazem dois usos entendidos como 'indevidos': uso 'indevido' de álcool e outras drogas e uso 'indevido' de gênero.

Dito isso, cabe dizer que:

i) neste texto as políticas sociais são concebidas como instâncias centrais de organização do corpo individual e social, operando por meio de normalização e gestão

374 Estudos Feministas, Florianópolis, 23(2): 371-388, maio-agosto/2015 
17 Dagmar MEYER e Carin KLEIN, 2013, p. 4

${ }^{18}$ Harwood, 2009.

19 MEYER, 2008.

${ }^{20}$ MEYER, 2008, p. 148.

${ }^{21}$ FOUCAULT, 1999. de variadas dimensões "da vida cotidiana dos sujeitos aos quais se direcionam, educando-os para pensar, sentir e agir de certos modos e não de outros". ${ }^{17}$ Assim, as práticas assistenciais e educativas a elas vinculadas, as biopedagogias ${ }^{18}$ inscritas e prescritas por tais políticas investem sobre o corpo e a vida dos indivíduos e da população no sentido de instituir/incorporar 'modos de viver a vida', a partir dos quais se produz inclusão social, como já se disse, por meio de uma cidadania regulada. Destaque-se que uma das normalizações inscritas nos corpos por meio das políticas de inclusão social diz respeito às prescrições de gênero;

ii) este escrito afasta-se de abordagens que reduzem gênero a papéis e funções de homens e mulheres. Ao contrário, parte do entendimento de que o gênero atravessa a constituição e o funcionamento de serviços assistenciais, políitcas sociais, corporais e de subjetivação de uma sociedade..$^{19} \mathrm{O}$ argumento é, pois, o de que as práticas terapêuticas, as práticas de cuidado tecidas no interior das políticas de saúde, tendem a funcionar como práticas pedagógicas obstinadas a inscrever no corpo dos dissidentes um currículo de gênero, por meio do qual se pode retomar sua humanidade. $O$ argumento é também $O$ de que as políticas sociais tendem a se construir e a funcionar também de modo generificado. Ou seja, "um sistema de raciocínio generificado" ${ }^{20}$ parece se inscrever nos projetos institucionais, terapêuticos e corporais dos serviços que compõem as políticas de saúde, dividindo, hierarquizando, assegurando a formação de corpos e sujeitos sexuados, generificados e sexualizados.

Mas o cuidado oferecido pelos serviços que compõem a política pública de saúde funciona apenas sob o registro de prescrição e normalização de condutas? Essa é a sina a que estão fadados os arranjos corporais, tecidos no seio das políticas de saúde? Procurando pelas vibrações do corpo e da vida, do corpo do cuidado desenvolvido, nossos corpos se fazem pesquisa e escrita. Se o que se quer é fortalecer um cuidado antimanicomial em álcool e outras drogas, parece relevante desenvolver um olhar (de gênero) sobre modos de produção desse cuidado, analisando e acompanhando os territórios existenciais e de sociabilidade ali surgidos, as (des)aprendizagens corporais ali tecidas, as (des)feituras de gênero ali desenvolvidas.

\section{A face tanathos da biopolítica}

Michel Foucault ${ }^{21}$ propõe partir da análise das relações de poder a fim de mostrar como as relações de sujeição fabricam sujeitos, ou melhor, posições de sujeito. Ou seja, posicionar-se no plano das relações de poder para 
22 FOUCAULT, 1999, p. 33.

${ }^{23}$ Leon FARHI NETO, 2010.
${ }^{24}$ Contenção em que se precisa utilizar outras ferramentas além do corpo e das mãos, como, por exemplo, ataduras. ver como, histórica e praticamente, os sujeitos se constituem. Estudar as relações de poder

[...] no interior de práticas reais e efetivas. [...]. Como as coisas acontecem no momento mesmo, no nível, na altura do procedimento de sujeição, ou nesses processos contínuos e ininterruptos que sujeitam os corpos, dirigem os gestos, regem os comportamentos. Apreender a instância material da sujeição. ${ }^{22}$

Leon Farhi Neto, ${ }^{23}$ por sua vez, analisa cinco formulações foucaultianas de biopolítica. Ao fazê-lo, aponta saúde, raça, sexualidade, segurança e economia, respectivamente, como princípios de operacionalidade que tornam possíveis modos específicos de sujeição da população atrelados a determinados modos de produção de subjetividade: nas malhas de um poder biomédico, os sujeitos se subjetivam como sujeitos de um corpo organizado; do dispositivo da sexualidade, como sujeitos de um sexo rei; do dispositivo da guerra, como sujeitos pertencentes a uma raça; do dispositivo da segurança, como ovelhas em perigo; da governamentalidade econômica, como empresários de si.

Nessa direção, a opção foi iniciar a tessitura da trama desta escrita descrevendo uma cena pinçada de um campo de trabalho, formação e pesquisa (2007-2009 e 2012), na qual aparece o paradoxo que habita o coração das práticas biopolíticas. Em seu cuidado tão meticuloso, tão sistemático com a vida, um cuidado que intenta atingir o seu mais fino grão, desponta um paradoxo incontornável.

Aracaju, Centro de Atenção Psicossocial para Álcool e outras Drogas (CAPS AD), por volta do meio dia. Aos cuidados da equipe técnica encontrava-se uma usuária que estava em abuso de substância psicoativa. Apresentando estado intenso de agitação psicomotora, agredia verbalmente a equipe, que precisou utilizar contenção mecânica ${ }^{24}$ e solicitou remoção pelo Serviço de Atenção Móvel de Urgência (SAMU), a fim de encaminhá-la para a Urgência de um hospital local. Diante da contenção e da chegada do SAMU, outros/as usuários/as ficaram apreensivos/as, interferindo no manejo dos/as técnicos/as e pedindo que a soltassem e não a levassem para a clínica. Nesse momento, uma trabalhadora do CAPS AD dirige-se verbalmente à equipe do SAMU, alegando que a crise da usuária fora em decorrência de cuidado 'excessivo' prestado pela equipe do CAPS...

Outros olhos assistem à cena... Destacam-se os olhares de um/a usuário/a em particular. Bermudas abaixo do joelho, correntes de metal e anéis, sandálias e pés 'gastos', andar gingado, mancava sempre (o que aconteceu com esse corpo?). A usuária em abuso contida era sua amiga. A contenção e a presença do SAMU haviam Ihe gerado um

376 Estudos Feministas, Florianópolis, 23(2): 371-388, maio-agosto/2015 
clima de extrema apreensão, talvez porque, além de estarem contendo sua amiga, também fizesse lembrar das agressões físicas trocadas em casa com o seu irmão, cujas marcas corporais ainda eram visíveis. A 'gota d'água' foi ter presenciando a 'fala' da profissional do CAPS AD dirigida à equipe do SAMU... Explosão: exalta-se e dirige-se à trabalhadora, alegando que a usuária em crise é cidadã e que, por isso, tem o direito de ser cuidada. A trabalhadora, por sua vez, também se exalta e vai de encontro àquele corpo que parecia tentar resistir também com violência à violência ali vivenciada, ao que a profissional retruca também violentamente: "Você pensa que está falando com quem? Você acha que tenho medo de você? Isso não vai ficar assim. Você não me conhece".

Removida a usuária em crise, foram realizados os devidos encaminhamentos e esclarecimentos das intervenções realizadas junto aos/às usuários/as. Feito isso, a gestora local do CAPS AD solicitou uma reunião com todos/as trabalhadores/ as presentes no serviço para avaliação do manejo/ intervenções. A trabalhadora recusou-se a participar, referindo que ia chamar seu marido e que iria para casa. A reunião foi interrompida quando dois policiais adentraram o serviço, direcionando-se ao corpo que ousou resistir, agredindo verbalmente a trabalhadora do CAPS AD. Ressalte-se que um dos policiais se apresentava como marido da profissional e que ela se encontrava ao lado dele, apoiando a intervenção e dizendo: "diz agora para ele o que você me disse".

Em vez de um funcionamento 'marido preocupado', o que adentrou o CAPS foi o funcionamento policial: o coronel e seu ordenança. Na cintura, portava uma pistola fora do coldre. Um dedo em riste apontado, produzindo um/a bandido/ a trêmulo/a, onde se deveria 'ver' um/a usuário/a sendo cuidado/a. O coronel ordenava que o/a usuário/a repetisse na frente dele o que dissera para a profissional, sua esposa.

O coordenador do Projeto de Redução de Danos (PRD) frisou para os militares que aquela prática não era admissível/ legal dentro de um serviço de saúde, sobretudo, sem nenhuma ordem judicial. Mediante tal colocação, o coronel ressaltou que ele não estava no serviço como policial, mas sim como marido da profissional 'agredida'.

Depois de muita insistência, o coronel resolveu sair, entretanto, impôs a condição de antes conversar com seu amigo (e disse, assim, o nome de um trabalhador do CAPS AD). O coronel saudou o trabalhador, seu amigo, e pediu que ele cuidasse da sua mulher e comunicasse-lhe sobre qualquer episódio e dificuldade que pudesse haver dentro do CAPS. Os militares foram acompanhados até a portaria do serviço, quando o coronel, em tom de voz imperativo, disse para o coordenador do PRD e a gestora local do CAPS 
${ }^{25}$ FOUCAULT, 1999, p. 295.

${ }^{26}$ FOUCAULT, 1999, p. 295.

${ }^{27}$ FOUCAULT, 1999
29 Georgio AGAMBEN, 2002, p. 149.

${ }^{30}$ FOUCAULT, 1999 , p. 306
$A D$ que, se não conseguirem oferecer segurança para os seus profissionais, "joguem a toalha". O coronel inferiu, ainda, que a gestora deveria ser casada, apontando para outras trabalhadoras, fazendo a mesma inferência e verbalizando que, se a segurança não for garantida, ao menos seja garantida a entrada dos maridos no CAPS.

Como se tateando sentidos na cena, parece caber perguntar: se o/a usuário/a tivesse extrapolado a agressão verbal, que conduta 'autorizaria' no policial que o/a transfigura em bandido/a? Que mecanismos, que racionalidade autoriza, compele força à farda, justificando seus excessos? Por meio de que jogo se produzem as práticas, os gestos, os afetos, a sobreposição de papéis, a posição de sujeito homem, policial, marido e amigo que, em nome da defesa da vida dos/as seus/suas, sobrepujando legalidades, dá-se o direito de expor vidas à morte, como se a sua vida e a do corpo rendido estivessem num terreno fora de jurisdição?

No mesmo momento em que se edifica o biopoder como poder de "fazer viver e deixar morrer" 25 - um poder que é exercido do lado da vida, que "é cada vez mais o direito de intervir para fazer viver, e na maneira de viver, e no 'como' da vida"; ${ }^{26}$ um poder imbuído de dar forma à vida, de cuidála, de geri-la, de majorar suas forças no limite de seu exercício -, localizam-se paradoxos. Foucault ${ }^{27}$ usa como exemplos a bomba atômica, a fabricação de vírus incontroláveis e universalmente destruidores para dimensionar o paradoxo incontornável que é o de um exercício de poder que é capaz de suprimir a própria vida para assegurá-la. Tem-se, assim, "o excesso do biopoder sobre o direito soberano, um excesso que aparece quando é dada a possibilidade humana técnica e política, não apenas de organizar a vida, mas de fazê-la proliferar e, no limite, suprimi-la". ${ }^{28}$

Nesse cruzamento entre intervenção de soberania estatal sobre vidas, incidindo sobre o ponto em que elas cessam de ser politicamente relevantes e a tarefa também estatal de zelar pelo corpo biológico da população, é nessa interseção que a biopolítica da população, preocupada em gerir o corpo social, converte-se em tanatopolítica: "quando a vida torna-se o valor político supremo coloca-se aí também o problema de seu desvalor". ${ }^{29}$ Eis o caráter paradoxal da biopolítica: ao passo que produz o campo de uma vida que precisa ser excessivamente cuidada, organizada, otimizada biologicamente, instaura um excesso do biopoder sobre o poder soberano, a partir do qual se pode matar quem quer que seja, inclusive os seus próprios membros, se estes constituírem fontes de perigo.

Ressalte-se que não se entende por 'matar' apenas o "assassínio direto": ${ }^{30}$ por tirar a vida, entende-se aqui expor à morte, multiplicar, para alguns o risco de morte. "Para fazer 
viver, para incrementar o cuidado purificador da vida, pode${ }^{31}$ Cesar CANDIOTTO, 2011 , p. 87. se e, em algumas situações, permite-se deixar morrer" ${ }^{31}$ Em todo o caso, assassínios diretos não se configurariam em homicídio, já que se trata de corpos matáveis, sobre os quais qualquer um pode exercer soberania, embora assassinatos ocorreram e ocorrem: nas penitenciárias e nos hospitais psiquiátricos de ainda hoje, no cotidiano das ruas de nossas cidades. Por matar, sobretudo, entendem-se os pequenos assassínios indiretos sob a lógica da irreparável exposição de vidas que se tecem em discrepância ao mandato de organização corporal numa relação de abandono: abandonar ao perecimento aqueles/as considerados/as desnecessários/as ou ameaçadores/as "da vida que se pretende

${ }^{32}$ CANDIOTIO, 2011 , p. 96.

${ }^{33}$ Luis CASTIEL, 2011 ; e FOUCAULT, 2008b.

${ }^{34}$ CANDIOTTO, 2011 , p. 96.

${ }^{35}$ AGAMBEN, 2002. positivar, ao modo de uma 'inclusão excludente'":32 em arenas biopolíticas contemporâneas, na cruzada rumo ao corpo e à saúde perfeita, os corpos humanos precisam engajarse na cultura e na educação do risco e do empreendedorismo de si. ${ }^{33}$ Os corpos humanos necessitam purificar-se cotidianamente de todos os males, sob pena de serem identificados como discrepantes e, assim, precisarem ser (re)incluídos socialmente na economia social de mercado, posto que nela não pode haver o ingovernável.

Ou, ao modo de uma exclusão includente, tais corpos discrepantes, na teimosia de não se engajarem a tal economia social, são posicionados como vidas matáveis, sendo necessário bani-los "no sentido de que, após abandonados, sejam suspendidas suas garantias previstas no ordenamento jurídico vigente. Abandonado, o indivíduo volta a ser capturado por quem o abandona a partir do exterior (ex capere) dos limites legais." 34 Ou seja, de uma forma ou de outra, em nome da segurança da população da qualidade de vida, corpos discrepantes sujeitam-se às malhas do Estado. Forjam-se, assim, o que Agamben ${ }^{35}$ intitula de "vidas nuas", vidas entregues à mercê de quem as abandona, ao mesmo tempo exclusas e inclusas, vidas dispensáveis e ao mesmo tempo capturáveis.

\section{Infâmias de gênero}

Ainda que sejam tomadas todas as precauções, apesar da reiteração constante das normas regulatórias que gerem as feituras corporais - sendo as normas de gênero fundamentais nesse processo de governo das condutas -, corpos escapam, colocando em xeque a pretensa naturalidade de tais normas, bem como a fixidez das extremidades dicotômicas: humano ou animal, homem ou mulher, masculino ou feminino, heterossexual ou homossexual. Tais corpos e seus movimentos tendem a ser logo capturados, identificados como corpos ilegítimos, imorais, patológicos, impróprios, "corpos 
${ }^{36}$ Judith BUTLER, 2007; Guacira LOURO, 2004; e PARAÍSO, 2011.

${ }^{37}$ LOURO, 2004, p. 16.

${ }^{39}$ Georges CANGUILHEM, 1978.

abjetos"36 em relação às condutas de gênero, indicando o limite que não pode ser ultrapassado. Em outros termos, aqueles que oscilam, hesitam, inventam caminhos outros e ousam trilhá-los são tidos como ameaças, suspeitos, "alvos privilegiados de pedagogias corretivas" ${ }^{37}$ voltadas para puni-los, salvá-los, curá-los, reabilitá-los, reeducá-los, reinseri-los sob o rótulo de identidades 'dissidentes'.

O/a usuário/a - corpo da cena condutora deste artigo, corpo usuário de drogas, corpo usuário de um serviço de saúde transfigurado, na cena, em bandido por ousar questionar a condução de uma contenção realizada por representantes do Estado - parece macular a forma-Homem à qual os corpos 'humanos' se tecem acoplados: esse corpo é um corpo que traz em sua superfície marcas de desleixo, de desregramentos e excessos cometidos, de vícios, um corpo à mercê dos perigos dos prazeres do uso de álcool e outras drogas. Em sua carne, encontram-se expostas ameaças ao bem-estar do povo da qualidade de vida, da população da vida ativa. Trata-se, pois, de um corpo que se desviou das biopedagogias, um corpo não engajado ao projeto estatal e mercadológico de feitura de corpos-empresas, de produção de indivíduos empreendedores de si, sujeitos e corpos ração do capital. Trata-se de um corpo que flutua entre vida e morte, corpo habitante da zona de indeterminação entre o homem e o animal, vida nua que precisa, portanto, ser banida da comunidade humana. Vida em suspensão, que excepciona e extravasa um real pré-fabricado de formas de vida modeladas. Vida definida por sua simbiose com a morte, sem, porém, pertencer ainda ao mundo dos cadáveres: um morto-vivente. O que fazer com corpos como esse que maculam o projeto purificador rumo à saúde e ao corpo perfeito, ao qual se encontram engajados corpos empreendedores de si, corpos que tem suas condutas governadas pela economia do biopoder?

Tomando o corpo como fio condutor de nossas análises, justamente por ser ele espaço de tensão entre formas de sujeição e forças de subjetivação/experimentação; e pensando gênero como norma regulatória fundamental no processo de feitura de corpos organizados e governáveis, mas também como categoria analisadora de paisagens corporais inéditas que ousam desfazer o gênero dado, ${ }^{38}$ debochar das normas regulatórias, desnaturalizando-as pela (auto)produção de normatividades ${ }^{39}$ inclusive de gênero, o objetivo é o de seguir movimentos de (re)existências corporais tecidos por profissionais e usuários/as no próprio bojo das políticas sociais. Mais do que isso, a finalidade foi - e é - a de rastrear outras feituras do corpo institucional e do cuidado oferecido pelas políticas de saúde. Entendendo, então, corpo e gênero como construções político-culturais, mas também político-éticas, na 
${ }^{41}$ FOUCAULT, $2001 \mathrm{~b}$.

${ }^{42}$ AGAMBEN, 2002.

${ }^{43}$ BUTLER, 2007

${ }^{44}$ FOUCAULT, 2006a. medida em que se trata de dar forma à vida e ao corpo, almejamos, pois, em nossas inserções de pesquisa e profissionais no interior de políticas de saúde, rastrear acontecimentos corporais:

O que se deve entender por 'acontecimentalização'? Uma ruptura absolutamente evidente, em primeiro lugar. Ali onde se estaria bastante tentado a se referir [...] a uma evidência se impondo da mesma maneira para todos, trata-se de fazer surgir uma 'singularidade'. Mostrar que não era tão necessário assim..$^{40}$

Aquele corpo da cena-acontecimento narrada no início do texto, corpo que 'ousa' barrar a conduta de uma trabalhadora, mulher, mãe, com residência fixa e poder de endividar-se, empresária de si, cidadã, esse corpo senão foi alvo de uma coerção disfarçada de cuidado, é alvejado por repressão policial. O coronel adentra o CAPS AD e intervém sobre tal corpo, ameaçando-o, contendo-o, coagindo-o. Por meio da dupla função de sujeito zelador da segurança da população e marido protetor, ele parece proteger-se a si mesmo do risco de ser tentado por devires, tornando-se outro, abrindo-se ao outro de seu 'próprio' corpo, muito bem delimitado, diga-se de passagem.

Bermudas e camisetas largas, correntes de metal e anéis adornam o corpo do/a usuário/a da cena-acontecimento; o rap é o estilo musical de sua preferência; cabelos curtos, voz grave e rouca, sorriso malandro misturado a um ar sisudo; palavras poucas e contundentes; olhar altivo, andar gingado mesclado a um mancar permanente; sandálias e pés 'gastos', que fazem lembrar os pés de tantos outros/as usuários/as do CAPS AD. Um ingrediente a mais 'revela' que esse corpo usuário de drogas e de CAPS, de periferia, desempregado, sem poder de endividamento, esse corpo que se revolta contra a fala da trabalhadora, é um "anormal", ${ }^{41}$ um "homo sacer", ${ }^{42}$ um corpo "abjeto", ${ }^{43}$ um "infame", ${ }^{44}$ que não existe para outra coisa senão para assinalar o limite do humano, para delimitar a fronteira de vidas dignas de serem vividas; um corpo desviante que precisa de tutela a fim de desligar-se de sua animalidade e trilhar caminhos humanos. Além de todas as características citadas acima, esse corpo é identificado como um corpo de mulher: uma usuária. Uma usuária com 'trejeitos' masculinizados e gosto pelas mulheres como parceria sexual. Mas um corpo-mulher não é para ser feminino - um feminino essencializado, diga-se de passagem - e para desejar sexualmente corpos-homens? Não é este o caso. Se não o é, a ousadia desse corpo, e de outros que figuram ali no CAPS AD, de ter se 'apropriado', ter se feito a partir de elementos de masculinidades não precisaria ser contida? Precisaria? 
${ }^{45}$ FOUCAULT, $2001 \mathrm{~b}$.

${ }^{46}$ FOUCAULT, 2006a.

${ }^{47}$ BUTLER, 2007; LOURO, 2004, 2007
Um corpo que faz uso considerado 'indevido' de álcool e outras drogas como também uso 'indevido' de gênero. À primeira vista, o cuidar desse corpo parece articularse com a necessidade de formatar corpos, de culpabilizar sujeitos e seus corpos, individualizá-los, corrigir/(re)abilitar suas condutas, trazer as vidas infames para a claridade do mundo humano, um mundo regulado por normas de gênero, um mundo supostamente sem drogas. Para tanto, traduzido por saberes especialistas que circulam no bojo das políticas de saúde, esse corpo é identificado como anormal, ${ }^{45} \mathrm{como}$ vida infame $^{46}$ indigna de ser vivida, posto que ultrapassou um possível pré-estruturado para os corpos humanos, precisando, por isso, ser submetido a práticas de saúde a fim de ser corrigido, reconduzido, normalizado, incluído.

Em outros termos, tachados como usuários de CAPS e de álcool e outras drogas, corpos tendem a sufocar numa emboscada cujos limites identitários são dados do seguinte modo: de um lado, a humanidade, à qual se pretende, com o 'tratamento', que eles retornem a fazer parte, colando-se à forma-Homem, corpo sexuado e generificado, heterossexual, trabalhador, consumidor, empreendedor de si; de outro lado, estão acoplados à identidade-abjeção, ${ }^{47}$ "dependente químico', corpo usuário de álcool e outras drogas, identidade que 'sutilmente' assinala a animalidade desses corpos. Expondo seus corpos às políticas de saúde, práticas de poder o iluminam, intervêm sobre eles na tentativa de produzir mudanças em seus 'estilos de vida', rumo à sua qualificação: qualificação desses corpos e dessas vidas. Mediante o poder de inscrever condutas por meio do acionamento de pedagogias corporais, de biopedagogias, tais práticas (de saúde) irão decidir entre a animalização desses corpos -, caso eles se mantenham não desejando o cuidado e o arreio -, e, assim, justificar a sua morte; ou entre a reanimação desses falsos vivos, humanizando-os, restabelecendo sua saúde, mediante vigilância cotidiana, inclusive dos próprios corpos sobre si mesmos e, com ela, sua humanidade, permitindo sua 'integração' à cidade, ao mundo humano.

(Des)territorializações e (des)aprendizagens
de gênero: pela subversão do corpo gene-
rificado das políticas de inclusão em saúde

O corpo da cena, em suas feituras de gênero, é um corpo fronteiriço, um corpo que parece debochar das normas regulatórias, sua expressão aponta para a desnaturalização das tais normas, sua exposição problematiza a evidência dessas normas. Num primeiro momento, num primeiro ímpeto, práticas de cuidado almejam tutelar esse corpo, corrigi-lo, purificá-lo, torná-lo mais claro, mais humano, mais gênero.

382 Estudos Feministas, Florianópolis, 23(2): 371-388, maio-agosto/2015 
${ }^{48}$ Gilles DELEUZE 1992.

${ }^{49}$ FOUCAULT, 2006a; e Antonio BAPTISTA, 2010.

${ }^{50}$ LOURO, 2004; BUTLER, 2007; e Suely ROLNIK, 2006.

${ }^{51}$ Clarice LISPECTOR, 2009, p. 56

52 LISPECTOR, p. 56.

${ }^{53}$ Peter PELBART, 2003.

${ }^{54}$ Berenice BENTO, 2006, p. 85.

${ }^{55}$ BENTO, 2006, p. 85.
No entanto, no próprio bojo das políticas de saúde, funcionam práticas de cuidado e de pesquisa também fronteiriças que almejam seguir esses corpos em suas fronteiras, intencionam habitar fronteiras, desenvolver, como diria Gilles Deleuze, ${ }^{48}$ "uma micropolítica das fronteiras", região onde a vida brota.

O objetivo de nossos empreendimentos de pesquisa tende a ser, assim, o de tentar encontrar a noite dos corpos infames ${ }^{49}$ usuários de políticas de saúde, a noite do corpo de profissionais, a noite do corpo do cuidado, a noite do corpo da pesquisa e da escrita. Encontrar a noite, aquele espaço conflitante e impessoal em que o corpo se verga, resiste ao exercício de um poder que intenta reiteradamente marcá-lo, delimitá-lo, extrair sua força para alimentar-se, identificá-lo, aquele espaço em que o corpo (re)existe. Então, a busca foi - e ainda é - por zonas em que se abre a possibilidade de experimentação desse corpo 'estranho'-queervibrátil, ${ }^{50}$ carne-lama "ainda úmida e ainda viva", ${ }^{51}$ que brota a remexer, "com lentidão insuportável", ${ }^{2}$ as raízes identitárias de corpos fabricados por práticas e normas sociais regulatórias.

Nas políticas e nos serviços de saúde, na feitura do corpo do cuidado, o convite à (re)existência de práticas de cuidado e de pesquisa é o de parar por um momento de ter cuidado com os perigos que corpos infames podem oferecer para 'nossos' corpos e rastrear 'outros' trajetos corporais em ensaios existenciais - inclusive do corpo do cuidado, entendendo que também ele se trata de uma montagem entre formas e forças. Seguir linhas que compõem uma resistência ativa, a qual diz respeito justamente à potência dos corpos, das vidas, de sua capacidade de diferir, de contagiar, de produzir alianças, de fabular mundos e vidas no seio desse momento histórico-político de segregação, homogeneização da vida e "perda de mundo", dado que todos os corpos 'devem' se gestar colados a um e único mundo do capital globalizado. ${ }^{53}$

O corpo da cena: uma "masculinidade sem homens". ${ }^{54}$ Um corpo híbrido, de fronteira que parodia o gênero por meio de "citações descontextualizadas de um referencial biológico". ${ }^{55}$ (Re)existências de gênero: o trajeto de vidas infames pede por ensaios, pela trama de arranjos corporais, inclusive de gênero, que parecem compor outras marcas além das de sujeição. Por entre 'rostos verdadeiros' de masculinidades e feminilidades, essa masculinidade sem homem que habita o ambiente 'masculinizado' de um serviço de saúde, a saber, um CAPS AD, se tece como masculinidade infame: esse masculino que subverte um corpo que careceria ser feito feminino, que necessitaria tecer-se reiterando a sina de um determinado feminino que deveria ser seu destino, ali deixa 
${ }^{56}$ PARAÍSO, 2011.

${ }^{57}$ BENTO, 2006, p. 16.

${ }^{58}$ Heliana RODRIGUES, 2010, p. 195.

${ }^{59}$ ROLNIK, 1998, p. 63.

${ }^{60}$ Felix DELEUZE e GUATTARI, 1997, p. 23.

${ }^{61}$ Dagoberto MACHADO, 2011 , p. 77. rastros que trazem consigo a força de desfazer o já feito e o já dado pelas normas regulatórias de gênero, ${ }^{56}$ de interferir na paisagem humana instituída como única, legítima, caminho reto e universal, mostrando com o seu corpo que "há muitas possibilidades de se [des]fazer gênero". ${ }^{57}$

Para desenvolver análise/pesquisa, para produzir cuidado em saúde de corpos também fronteiriços, está-se apontando a habitação de um outro plano, também fronteiriço, em vez de situado nas extremidades já dadas: plano relacional, mas não um relacional de dois termos estabilizados; região virtual do 'entre' - "algo real, por mais que não esteja atualizado em estados de coisas" -, 58 a partir do qual e com o qual as formas assumem uma dada configuração instável; plano das forças, bem ali onde há composição de afetos, onde se podem captar "as pegadas dos fluxos do mundo no corpo" 59 e perturbar as figuras e formas vigentes. Nesse plano:

Estamos longe da produção filiativa, da reprodução hereditária, que só retém como diferenças uma simples dualidade dos sexos no seio de uma mesma espécie, e pequenas modificações ao longo das gerações. Para nós, ao contrário, há tantos sexos quanto termos em simbiose, tantas diferenças quanto elementos intervindo num processo de contágio. Sabemos que entre um homem e uma mulher passam muitos seres, que vêm de outros mundos, trazidos pelo vento, que fazem rizoma em torno das raízes, e não se deixam compreender em termos de reprodução, mas apenas de devir. ${ }^{60}$

Em outras palavras, em vez de se seguir submetendo corpos que ousam outras performances de gênero a práticas pedagógicas e a análises que tendem a identificá-los e fixálos como anormais, ou seja, como corpos que precisam ser conduzidos a fim de recompor o caminho da retidão dos humanos sexuados, encontros noturnos - clandestinos, menos afeitos à excessiva iluminação do biopoder - com esses corpos trazem, bem ali no bojo das políticas e do cuidado em saúde, a possibilidade de (des)aprendizagem, de abertura de corpos para o ensaio de outras formas de vida inclusive o corpo institucional, do cuidado e da pesquisa. A partir desses encontros, os corpos podem, assim, se despir do que foi aprendido por normas regulatórias e ensaiar outras performances mais mestiças, mais afeitas à hibridação, à aventura de outras experimentações corporais. "Com efeito sobre os corpos, um encontro ocorre entre corpos. [...] Algo passa entre os corpos que se encontram. Não se trata de ver, ter consciência ou muito menos pegar. Caçar este entre dos encontros é seguir a subjetivação". ${ }^{61}$ Está-se, pois, falando de uma experiência que, ao invés de fundar o sujeito, abre caminho para processos de (des)subjetivação. 
62 FOUCAULT, 2010a, p. 291. ${ }^{63}$ BUTLER, 2007; BENTO, 2006; e PARAÍSO, 2011.

${ }^{64}$ PARAÍSO, 2011 , p. 167.

65 PELBART, 2003, 2004.

66 PASSETTI, 2009, p. 131.

${ }^{67}$ FOUCAULT, 2006b.

${ }^{68}$ Elizabeth BARROS, 2005.

${ }^{69}$ De acordo com Foucault (2006b), o cuidado de si não é uma exigência de solidão e de separação do mundo, é, sim, uma prática social, um intensificador das relações sociais. "O cuidado de si não tem por finalidade cortar o eu do mundo, mas prepará-lo, em vista dos acontecimentos do mundo" (GROS, 2006, p. 651). Não se trata pois, de abster-se do mundo, mas de medir o lugar que se ocupa nele. Em outros termos, o cuidado de si é "aquilo que nos incita a agir bem, aquilo que nos constitul como o sujeito verdadeiro de nossos atos" (GROS, 2006, p. 651)

${ }^{70}$ Frédéric GROS, 2006, p. 635.
Nas zonas de brechas, parece haver possibilidade de composição de outras formas de vida e de normatividades corporais, as quais se produzem fora do cerco dos parâmetros dados pelo biopoder. Experimentações do (in)vivível: "o que é requerido é o máximo de intensidades e, ao mesmo tempo, de impossibilidade" 62 na tessitura de corpos que, quem sabe, podem "desfazer o gênero", ${ }^{63}$ desarranjar suas divisões e hierarquizações, lançar-se em outras performances, abrir-se para "um mundo pós-gênero". 64 Deslocamentos existem, insistem, persistem, subvertendo a paisagem corporal, genital, sexuada, generificada e sexualizada.

Assim, entre biopoder e biopotência, entre poder sobre a vida e a potência de dar forma à vida, ${ }^{65}$ nesse espaço paradoxal, o corpo desliza entre minguar ao ser exposto à luz do poder e dobrar o poder dobrando-se, excedendo-o, vazando, criando a desmedida, produzindo outros modos de existência, outras subjetivações, outras formas de viver e conviver, alçando um governo de si ao invés de prosseguir governado por outros, mesmo quando governa a si mesmo. Ensaios de existência, (re)existências dos corpos, do cuidado e da vida institucional, insurgências de um cuidado de si que se tece na relação com o outro:

As resistências na sociedade de controles contínuos e de comunicação constante ocupam pequenos espaços, promovem minúsculos acontecimentos no limiar de experimentações para além da borda. Esses espaços são compostos de forças vivas e também por acúmulo de desgastes. Trazem consigo apenas reservas de vida e de morte, presença do rompimento inevitável com o uniforme, o consenso e o comum. ${ }^{66}$

No bojo mesmo da política pública de saúde, pequenas bolhas de ar suspensas na terra árida da biopolítica neoliberal parecem se formar e fazer respirar, pedindo passagem para outros modos de cuidar e de educar, próximos do que Foucault, ${ }^{67}$ a partir do pensamento grego clássico, denominou tékne toû bíou. Ou seja, um cuidado-educação engajado com a constituição de um ethos, a partir da abertura dos corpos para os acontecimentos da vida. Em vez de uma fôrma de ação, ${ }^{68}$ um dar forma à vida, um cuidado-educação para a vida, entendido como exercício, como prova, como experiência que faz do mundo 69 "ocasião de transformação de si, o lugar de emergência de uma subjetividade."70 Um cuidado-educação como experimentação com força para transfigurar sobrevidas, a vida nua, a zoé da qual o governo biopolíico se vale, em vidas que assumem o risco de respirar outros ares menos rarefeitos, constituindo maneiras de viver singulares. Bem ali, em regiões fronteiriças e limiares, funcionando à deriva de formas de sujeição, forjam-se (re)e- 
xistências... (re)existências da clínica, dos corpos, do cuidado em saúde, do gênero, da vida.

\section{Referências}

AGAMBEN, Giorgio. Homo Sacer: O poder soberano e a vida nua. Belo Horizonte: UFMG, 2002.

BAPTISTA, Luis Antonio. "Noturnos Urbanos. Interpelações da literatura para uma ética de pesquisa". Revista Estudos e Pesquisas em Psicologia, n. 1, p. 103-117, $1^{\circ}$ sem. 2010.

BARROS, Maria Elizabeth. "Desafios ético-políticos para a formação dos profissionais de saúde: transdisciplinaridade e integralidade". In: PINHEIRO, Roseni; CECCIM, Ricardo; MATTOS, Ruben (Orgs.). Ensinar saúde: a integralidade e o SUS nos cursos de graduação na área da saúde. Rio de Janeiro: IMS/UERJ: CEPESQ: ABRASCO, 2005. p. 131-152.

BENTO, Berenice. A reinvenção do corpo: sexualidade e gênero na experiência transexual. Rio de Janeiro: Garamond, 2006.

BUTLER, Judith. "Corpos que pesam: sobre os limites discursivos do 'sexo'”. In: LOURO, Guacira Lopes (Org.). O corpo educado: pedagogias da sexualidade. Belo Horizonte: Autêntica, 2007. p. 151-172.

CANDIOTIO, Cesar. "Cuidado da vida e dispositivo de segurança: a atualidade da biopolítica". In: BRANCO, Guilherme Castelo; VEIGA-NETO, Alfredo (Orgs.). Foucault: filosofia \& política. Belo Horizonte: Autêntica Editora, 201 1. p. 81-96.

CARVALHO, Sérgio Rezende. "Reflexões sobre o tema da cidadania e a produção de subjetividade no SUS". In: CARVALHO, Ségio Rezende; BARROS, Maria Elizabeth; FERIGATO, Sabrina (Orgs.). Conexões: saúde coletiva e políticas da subjetividade. São Paulo: Aderaldo \& Rothschild, 2009. p. 23-41.

CASTIEL, Luis David. "Saúde, riscos e hiperprevenção". Acta Paulista de Enfermagem, v. 24, n. 4, p. vii-viii, 2011.

CANGUILHEM, Georges. O normal e o patológico. Rio de Janeiro: Forense Universitária, 1978.

CORAZZA, Sandra; SILVA, Tomaz Tadeu. "Manifesto por um pensamento da diferença na educação". In: Composições. Belo Horizonte: Autêntica Editora, 2003. p. 9-18.

DELEUZE, Gilles. Conversações (1972-1990). São Paulo: Editora 34, 1992. (Coleção Trans).

DELEUZE, Gilles; GUATTARI, Felix. "Devir-intenso, devir-animal, devir-imperceptível". In: . Mil platôs: capitalismo e esquizofrenia. v. 4. Rio de Janeiro: Editora 34, 1997. p. 11-114.

FARHI NETO, Leon. Biopolíticas: as formulações de Foucault. Florianópolis: Cidade Futura, 2010.

FOUCAULT, Michel. Em defesa da sociedade. São Paulo: Martins Fontes, 1999. (Coleção Tópicos).

386 Estudos Feministas, Florianópolis, 23(2): 371-388, maio-agosto/2015 

$2001 a$

Microfísica do poder. Rio de Janeiro: Edições Graal, . Os anormais. São Paulo: Martins Fontes, 2001 b.

"A vida dos homens infames". In: MOTTA, M. B. (Org.). Ditos \& Escritos IV:estratégia, saber-poder. Rio de Janeiro: Forense Universitária, 2006a. p. 203-222.

. A hermenêutica do sujeito. São Paulo: Martins Fontes, 2006b.

."Mesa-redonda em 20 de maio de 1978". In: MOTTA,

M. B. (Org.). Ditos \& Escritos IV:estratégia, saber-poder. Rio de Janeiro: Forense Universitária, 2006e. p. 335-351.

Segurança, território, população. São Paulo: Martins Fontes, 2008a.

. Nascimento da biopolítica. São Paulo: Martins Fontes, 2008b.

"O sujeito e o poder". In: DREYFUS, H. L.; RABINOW, P. Michel Foucault: uma trajetória filosófica: para além do estruturalismo e da hermenêutica. Rio de Janeiro: Forense Universitária, 2010. p. 273-295.

GROS, Frédéric. "Situação do curso". In: FOUCAULT, Michel. $A$ hermenêutica do sujeito. São Paulo: Martins Fontes, 2006. p. 611-661.

HARWOOD, Valerie. "Theorizing biopedagogies". In: WRIGHT, Jan; HARWOOD, Valerie (Eds.). Biopolitics and the 'obesity epidemic': governing bodies. New York, NY: Routledge, 2009. p. 15-30.

LISPECTOR, Clarice. A paixão segundo G.H. Rio de Janeiro: Rocco, 2009.

LOPES, Maura Corcini. "Norma, inclusão e governamentalidade neoliberal". In: BRANCO, Guilherme Castelo; VEIGA-NETO, Alfredo (Orgs). Foucault: filosofia \& política. Belo Horizonte: Autêntica Editora, 201 1. p. 283-298.

LOURO, Guacira Lopes. Um corpo estranho: ensaios sobre sexualidade e teoria queer. Belo Horizonte: Autêntica Editora, 2004.

. "Pedagogias da sexualidade". In: O corpo educado: pedagogias da sexualidade. Belo Horizonte: Autêntica Editora, 2007. p. 7-34.

MACHADO, Dagoberto. Movimentos na educação física: por uma ética dos corpos. Dissertação (Mestrado em Educação) - Programa de Pós-Graduação em Educação, Faculdade de Educação, Universidade Federal do Rio Grande do Sul, Porto Alegre, 2011.

MEYER, Dagmar Estermann. "Gênero e educação: teoria e política". In: LOURO, Guacira Lopes; FELIPE, Jane; GOELLNER, Silvana V. (Orgs). Corpo, gênero e sexualidade: um debate contemporâneo na educação. Petrópolis: Vozes, 2008. p. 9-27. 
PARAISO, Marlucy. "Raciocínios generificados no currículo escolar e possibilidades de aprender". In: LEITE, C. et al. (Orgs). Políticas, fundamentos e práticas do currículo. Porto: Porto Editora, 201 1. p. 147-160.

PASSETTI, Edson. Anarquismos e sociedade de controle. São Paulo: Cortez Editora, 2003.

"Foucault-antifascista, São Francisco de Sales-Guia e atitudes de parresiasta". In: RAGO, Margareth; VEIGANETO, Alfredo. (Orgs). Para uma vida não-fascista. Belo Horizonte: Autêntica Editora, 2009. p. 117-134.

PELBART, Peter Pál. Vida capital: ensaios de biopolítica. São Paulo: lluminuras, 2003.

"O corpo, a vida, a morte". In: PASSETTI, Edson. (Org.) Kafka, Foucault: sem medos. São Paulo: Ateliê Editorial, 2004. p. 139-156.

RODRIGUES, Heliana Conde. "A história oral como intercessor: em favor de uma dessujeição metodológica". Estudos e Pesquisas em Psicologia, v. 10, n. 1, p. 190-203, 2010.

ROLNIK, Suely. "Tristes gêneros". In: LINS, Daniel (Org.). A dominação masculina revisitada. Campinas: Papirus, 1998. p. 6368.

Cartografia sentimental: transformações contemporâneas do desejo. Porto Alegre: Sulina; Editora da UFRGS, 2006.

SCHEINVAR, Estela. "Biopolítica e judicialização das práticas de direitos: conselhos tutelares em análise". In: BRANCO, Guilherme Castelo; VEIGA-NETO, Alfredo (Orgs). Foucault: filosofia \& política. Belo Horizonte: Autêntica Editora, 2011. p. 143-152.

[Recebido em 7 de outubro de 2013, reapresentado em 17 de dezembro de 2014 e aceito para publicação em 5 de fevereiro de 2015]

\section{Beware of (and Care for) Bodies: a Look (of Gender) for Health Policies}

Abstract: The text aims to think the (mental) public health policies and its institutional mandate of social inclusion as part of a wider picture of the (neo) liberal biopolitics face, where life and human behavior are directed towards the market. In this context, those that have failed or have not engaged in making their bodies listed companies, appear as new patients, abnormal or infamous. The scope of care practices offered by health policies tends, in this way, to inscribe such infamous lives in pedagogies, particularly of gender and sexuality, including them in the social market economy. Looking for extensions of the body and life, this work developed a look (of gender) on modes of production of health care, particularly in alcohol and other drugs. Key words: Biopolitics; Public Health Policies; Social Inclusion; Body; Gender. 